\title{
Commentary: Ischemic left ventricular dysfunction needs durable complete surgical coronary revascularization
}

Tohru Asai, MD, PhD

\author{
From the Department of Cardiovascular Surgery, Juntendo University, Tokyo, Japan. \\ Disclosures: Author has nothing to disclose with regard to commercial support. \\ Received for publication May 13, 2019; accepted for publication May 13, 2019; available ahead of print June 21, \\ 2019. \\ Address for reprints: Tohru Asai, MD, PhD, Department of Cardiovascular Surgery, Juntendo University, 2-1-1, \\ Hongo, Bunkyo-ku, Tokyo 113-8421, Japan (E-mail: t.asai.jj@juntendo.ac.jp). \\ J Thorac Cardiovasc Surg 2020;159:1806 \\ $0022-5223 / \$ 36.00$ \\ Copyright (c) 2019 by The American Association for Thoracic Surgery \\ https://doi.org/10.1016/j.jtcvs.2019.05.047
}

Hwang and colleagues ${ }^{1}$ elegantly demonstrate improvement of segmental myocardial wall motion in patients with left ventricular dysfunction after surgical revascularization. The authors selected 67 patients with left ventricular dysfunction who underwent coronary artery bypass grafting (CABG), 66 patients by off-pump CABG and one by onpump CABG. Those 67 patients underwent serial cardiac magnetic resonance imaging with late gadolinium enhancement (LGE) preoperatively and at 3 months and 1 year after CABG. The myocardial damage grading scores using the transmural extent of LGE were evaluated on a 16segmental model. The authors found that improvements in segmental myocardial function occurred mostly within 3 months after surgery, and some within 1 year. It was noteworthy that one third of segments showing LGE $>50 \%$ still demonstrated functional improvement.

Gadolinium enhanced magnetic resonance imaging has been reported to be useful in distinguishing between reversible and irreversible myocardial ischemic injury regardless of wall motion abnormality. ${ }^{2}$ Among various methods of evaluating myocardial viability, as the authors mention, serial cardiac magnetic resonance imaging with LGE offers a distinct advantage in high resolution analysis of segmental status, with quantitative assessment. This well-designed study exploited this ability to make fine 16-segmental assessments into 5 stages, at 3 different times, before and after surgery. Additionally, the authors confirmed graft patency at 1 year after surgery, further validating their findings.

Cardiac surgeons who perform $\mathrm{CABG}$ tend to have different strategies, especially for infarcted areas of myocardium other than true fibrotic aneurysmal wall. However, the findings of this study indicate that patients with ischemic left ventricular dysfunction are the very cases in which we need to revascularize meticulously all target sites, without skipping bypassing for any akinetic myocardial segments, even those with some infarcted scar tissue.

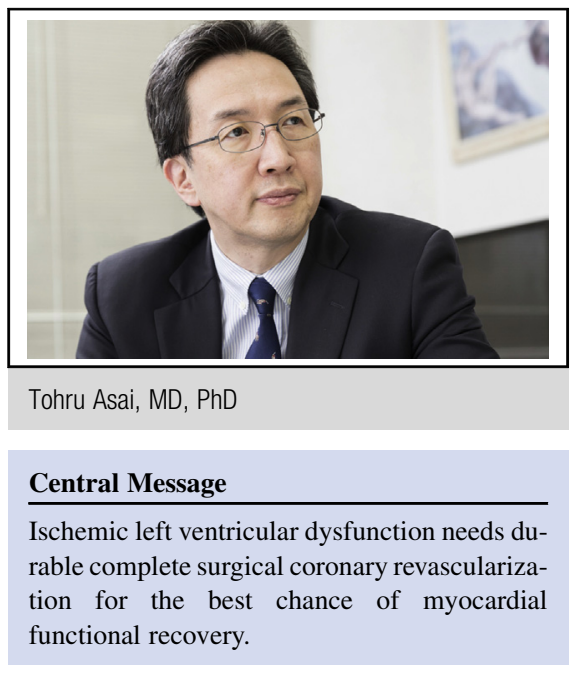

See Article page 1798 .
Although this study includes only a relatively small number and percentage of patients, with 67 patients $(7.6 \%)$ among the authors' 877 isolated CABG patients in single institution, they focused on patients with left ventricular ejection fraction $<0.35$, and their serial examinations were effectively presented. Their CABG strategy was anaortic off-pump CABG, mostly using composite grafting based on the left internal thoracic artery, and I wonder whether the speed of functional improvement might have been faster with a different grafting strategy. For example, might larger-caliber noncomposite graft conduits have been associated with faster functional recovery in the sickest patients? Future investigations may elucidate different functionalities of different conduits. However, we probably need to agree on the importance of their message; that is, to revascularize all potential target sites completely, especially for patients with left ventricular dysfunction.

\section{References}

1. Hwang HY, Yeom SY, Park EA, Lee W, Jang MJ, Kim KB. Serial magnetic resonance after surgical coronary revascularization for left ventricular dysfunction. $J$ Thorac Cardiovasc Surg. 2020;159:1798-805.

2. Kim RJ, Wu E, Rafael A, Chen EL, Parker MA, Simonetti O, et al. The use of contrast-enhanced magnetic resonance imaging to identify reversible myocardial dysfunction. N Engl J Med. 2000;343:1445-53. 